\title{
PODSTAWY FENOMENOLOGII POZNANIA A PROBLEM JĘZYKA. UWAGI DO KSIĄŻKI WITOLDA PŁOTKI STUDIA Z FENOMENOLOGII POZNANIA
}

\begin{abstract}
Streszczenie. Celem niniejszego artykułu jest dyskusja z niektórymi tezami zawartymi w książce Witolda Płotki, Studia z fenomenologii poznania. Transcedentalna filozofia Edmunda Husserla a problem wiedzy. Zostaje podjęta kwestia dotyczącą miejsca i znaczenia rozważań nad językiem w kontekście fenomenologii Husserlowskiej. Autor zastanawia się, czy język jest medium przezroczystym, czy jednak jest on elementem konstytutywnym dla treści i charakteru doświadczenia.
\end{abstract}

Słowa kluczowe: język, fenomenologia, wnioskowanie materialne, wiedza, działanie

Celem Witolda Płotki w książce Studia z fenomenologii poznania. Transcedentalna filozofia Edmunda Husserla a problem wiedzy ${ }^{1}$ jest próba odpowiedzi na dwa podstawowe pytania epistemologiczne: czym jest poznanie oraz czym jest wiedza. Autor sugestywnie wskazuje na konieczność przyjęcia perspektywy fenomenologicznej epistemologii, opartej na postulacie badań podmiotowo-przedmiotowych lub mówiąc bardziej technicznie: noetyczno-noematycznych.

Pierwszy rozdzial, zatytułowany Zakres fenomenologii poznania, ma charakter wprowadzający. Charakteryzuje pojęcie i przedmiot fenomenologii poznania, zwracając uwagę na jej odmienność w stosunku do innych działów ogólnie pojętej filozofii poznania, takich jak epistemologia czy współczesne teorie wiedzy. Fenomenologia $\mathrm{w}$ sensie ścisłym nie jest teorią rozumianą tradycyjnie jako system dedukcyjnie powiązanych twierdzeń, ale badaniem wstępnym,

1 W. Płotka, Studia z fenomenologii poznania. Transcendentalna filozofia Edmunda Husserla a problem wiedzy, Gdańsk 2015. 
które opiera się na wprowadzonej przez Husserla perspektywie ejdetyczno-transcendentalnej.

Rozdział drugi, Gtówne wyzwania fenomenologii poznania, kontynuuje i zarazem precyzuje dociekania rozpoczęte w rozdziale pierwszym. Autor odróżnia mocne i umiarkowane warunki analizy teoriopoznawczej, wiążąc pierwsze z kartezjańską pewnością w uzasadnianiu wiedzy, a drugie $z$ rezygnacją $z$ owego dogmatycznego żądania ${ }^{2}$. Ważne jest tutaj wykazanie transcendentalnego, a więc nie-empirycznego charakteru dociekań fenomenologicznych. Temu zagadnieniu poświęcony jest trzeci rozdział rozprawy, noszący tytuł Fenomenologia wobec sceptycyzmu: uzasadnienie fenomenologii poznania w swietle krytyki.

Kolejny rozdział - Opis, eidos i transcendencja: metodologia fenomenologii poznania - dookreśla specyfikę Husserlowskiego transcendentalizmu w oparciu o charakterystykę postulatu analiz opisowo-ejdetycznych. Zostaje w nim wykazany normatywny charakter analiz fenomenologicznych oraz następuje podkreślenie roli i znaczenia specjalnego narzędzia metodologicznego, jakim jest redukcja ${ }^{3}$. Przeprowadzenie zabiegu redukcji pozwala ująć istotę poznania w kategoriach relacji sensu i obiektu, czyli korelacji noetyczno-noematycznej. Rezultatem opisowo-ejdetycznej analizy tej korelacji są sądy, które wyrażają prawa istotowe. Płotka zaznacza, że praw istotowych nie należy utożsamiać z sądami analitycznymi

2 Odróżnienie mocnych i umiarkowanych warunków analizy teoriopoznawczej ściśle łączy się z wyróżnionymi przez Ernsta Tugendhata motywem dogmatycznym - kartezjańskim oraz motywem krytycznym; oba miały od początku być obecne w myśli Edmunda Husserla. Problem ten jednak wymaga dalszych badań, które znacznie wykraczają poza perspektywę przyjętą w tym artykule. Por. E. Tugendhat, Der Wahrheitsbegriff bei Husserl und Heidegger, Berlin 1970.

3 W innym miejscu Witold Płotka określił redukcję jako zapytywanie. Por. W. Płotka, Redukcja fenomenologiczna jako zapytywanie. Fenomenologia Husserla a problem pytania, Przegląd Filozoficzny. Nowa Seria 85(2013)1, 173-190. Szkoda, że autor nie pokusił się w swojej książce o nawiązanie do interesujących tez przedstawionych w tym artykule. 
lub sądami wyrażającymi prawa przyrody. Nie podaje jednak za tą tezą mocnych argumentów.

Pierwsze cztery rozdziały Studiów ściśle odnoszą się do metodologii badań fenomenologicznych. Rozdział piąty, zatytułowany Relacja poznawcza jako reprezentacja: elementy ogólnej fenomenologii poznania, otwiera najciekawszą, przedmiotową część pracy. Autor na tle dyskusji z tezą Huberta Dreyfusa, który zrównuje teorię Husserla z reprezentacjonizmem Jerry’ego Fodora, określa, czym jest treść $\mathrm{w}$ ujęciu fenomenologii poznania.

Rozdział szósty, pod tytułem Transcendentalna interpretacja wiedzy i poznania: ku prezentacjonizmowi, kontynuuje rozważania z rozdziału piątego. Autor podkreśla, że w fenomenologii przedmiot jest dany wprost, w swej prezencji, a nie za pośrednictwem czegoś trzeciego. To poprzez akty podmiot odnosi się do przedmiotu. Ważny jest tutaj moment tetyczny, czyli charakter uznania tego, co dane. Odnosi się on do przekonania, że dany przedmiot ,jakos" istnieje. Pojawia się niejasność: czy należy go zatem wiązać z aktem sądzenia, czyli stwierdzenia zachodzenia czegoś? Płotka pisze, że „to nie język umożliwia noematy, lecz te ostatnie leżą u podstaw użycia języka"4. Niestety, pozostawia nas z tym przekonaniem bez głębszego uzasadnienia. W dalszej części rozdziału autor uzupełnia swoje rozważania o problem tzw. horyzontów, które współokreślają to, co poznane. Zgodnie z poglądem Płotki, nie mają one charakteru językowego, co oznacza, że wiedza zawarta w języku nie stanowi potencjalnego horyzontu, umożliwiającego rozumienie i poznanie danego przedmiotu.

Rozdziały siódmy i ósmy, zatytułowane odpowiednio Analiza podstawowych źódet poznania: elementy szczegótowej fenomenologii poznania (I) oraz Analiza zawodnych źródet poznania: elementy szczegótowej fenomenologii poznania (II) tworzą syntetyczną całość i stanowią w moim odczuciu centralną i najbardziej interesującą część pracy. Rozprawia się tutaj o rodzajach aktów poznania. Rozdział

4 W. Płotka, Studia z fenomenologii poznania, dz. cyt., 163. 
siódmy poświęcony jest źródłom, dostarczającym taką wiedzę, której nie da się sprowadzić do innych źródeł. Są to: percepcja, naoczność kategorialna, poznanie a priori, pamięć oraz refleksja. W kolejnym rozdziale dyskutowane są tzw. zawodne źródła poznania, do których można zaliczyć przedrefleksyjną wiedzę operacyjną, wiedzę o innych podmiotach, a wreszcie potoczną oraz fenomenalną.

Ostatnią, zwieńczającą częścią monografii, jest rozdział dziewiąty, zatytułowany Fenomenologia prawdy i oczywistości. Poruszone są w nim trzy powiązane problemy: 1) jak należy opisać prawdę?; 2) czym jest oczywistość?; 3) w jaki sposób oczywistość konstytuuje poznanie jako prawdziwe?. Płotka zwraca uwagę na problem, który wydaje się ściśle odróżniać projekt fenomenologiczny od projektów analitycznych czy neopragmatycznych w ten sposób, że „przedstawione problemy i zadanie analizy prawdy poprzedza dociekanie stricte teoriopoznawcze, ponieważ opis sposobów konstytucji prawdy wyprzedza próbę jej zdefiniowania"5. Autor uzasadnia, że fenomenologia jest fundacjonalizmem umiarkowanym, co w jej przypadku oznacza, że poznanie ejdetyczne nie jest niezawodne i że jest korygowalne.

W Zakończeniu Witold Płotka podsumowuje swoje badania, podkreślając ich rekonstrukcyjny i zarazem twórczy charakter w odniesieniu do filozoficznego projektu Edmunda Husserla, który $\mathrm{i}$ - tutaj należy zgodzić się z autorem - „wciąż pozostaje relatywnie mało znany"6 oraz - dodam od siebie - wielokrotnie przeinaczany i niezrozumiany.

Chciałbym teraz uzasadnić, dlaczego uważam pracę Witolda Płotki za ważną. Głównym powodem jest sama idea fenomenologii poznania ucieleśniona w Studiach. Oczywiście problem ten był wielokrotnie poruszany przez wielu autorów, przy różnych okazjach, wystarczy wspomnieć Ingardenowskie $U$ podstaw teorii poznania

5 Tamże, 249.

6 Tamże, 284. 
oraz Studia z teorii poznania, jednak jak dotąd nikt nie pokusił się o takie metodologiczno-ejdetyczne ufundowanie jak Płotka. Zaletą tego opracowania jest wykorzystanie nauk Husserlowskich na wielu poziomach, w kontekście współczesnych projektów filozoficznych, takich jak analityczna teoria wiedzy czy inspirowana kognitywistyką filozofia umysłu.

Podkreślenie ważności i potrzeby przeprowadzania kolejnych zabiegów redukcji, wykazanie, że problematyka teoriopoznawcza in statu nascendi wyprzedza bądź neutralizuje problemy realizmu i idealizmu różnej maści oraz uzasadnienie ważności przedmiotowej i metaprzedmiotowej zagadnień teoriopoznawczych, które nie są sprowadzalne do analizy wiedzy, zdań epistemicznych czy analizy uwarunkowań ewolucyjnych bądź społecznych, to kolejne powody, dla których warto po Studia sięgnąć.

Na początek należy zwrócić uwagę na dwie słabości „zewnętrzne” dotyczące książki Witolda Płotki. Pierwszą z nich jest brak bibliografii i indeksów. W pracy tego formatu takie braki są nie do przyjęcia. W przypadku tak bogatej w cytowania pracy jest to wielka niedogodność.

Niefortunnym wydaje się tytuł, jaki Płotka nadał swojej książce. Słowo „studia” sugeruje raczej zbiór tekstów niż jednolitą pracę. Tak jednak nie jest. Książka od początku do końca jest przemyślaną kompozycją i nie ma w żadnym stopniu eklektycznego charakteru. Jednak tak sformułowany tytuł może wprowadzić czytelnika w błąd.

Przejdę teraz do krytyki merytorycznej Studiów z fenomenologii poznania. Skoncentruję się na jednym, w moim odczuciu najważniejszym wątku, a dokładniej jego braku na kartach monografii. Jest nim język i jego miejsce w analizach teoriopoznawczych - zarówno jako czynnika wiedzotwórczego, jak i przedmiotu badań. Przeglądając Spis treści nie natkniemy się na żaden podrozdział poświęcony rozważaniom nad językiem. Jest to dość symptomatyczne, bowiem klasyczna fenomenologia problem języka pozostawiła na antypodach swoich rozważań. Wydaje się to jednak niezrozumiałe. Nie ma tutaj 
miejsca, by choć pobieżnie tym problemem się zająć. Stawiam sobie cel skromniejszy, ale wydaje się, że dosyć istotny. Wejdę z autorem $\mathrm{w}$ polemikę na temat nieuwzględnienia przez niego czynników językowych. Odeprę od razu zarzut, który ktoś może mi postawić, że atakuję autora za brak analiz przedmiotu, którym ten się nie zajmował, tak jakbym wytykał mu brak np. rozważań kontekstu społeczno-kulturowego powstawania wiedzy. Tak jednak nie jest. Język, jeśli mogę się tak wyrazić, w Studiach gra rolę dalekiego krewnego, którego wstydzi się rodzina. Dlaczego tak uważam? W wielu miejscach, co będę chciał wykazać, Płotka dochodzi do problemu języka, ale ostatecznie go unika.

Rozpocznę od przytaczanych przez Płotkę słów Romana Ingardena, które wydają się dobrze wyrażać pewną tendencję obecną $\mathrm{w}$ fenomenologicznej refleksji nad własną metodą. Ingarden powiada: "Jest to metoda czysto opisowa, której zadaniem jest wykryć w odpowiednim doświadczeniu (bezpośrednim poznawaniu) naocznie występujące rysy charakterystyczne czy właściwości przedmiotu badania i »opisać« go, to znaczy podać, resp. nazwać te właśnie rysy i przypisać je temu przedmiotowi w zdaniach, które nie przesądzają żadnych właściwości nie danych w doświadczeniu lub tylko wynikających $z$ takiej lub innej czysto myślowej teorii. Metoda ta więc unika wszelkich hipotez lub założeń czysto pojęciowych, unika również - przynajmniej do chwili, gdy uzyskane są poznawcze wyniki opisowe - wszelkich czysto pojęciowych rozumowań czy wnioskowań, ogranicza się przeto do stwierdzenia i opisu tego tylko co jest dane »bezpośrednio «w odpowiedniej naoczności 7 ".

Husserl napisawszy Badania logiczne uświadomił sobie, że pisząc tę pracę, korzystał z gotowych znaczeń zawartych w pojęciach, których używał. $Z$ tego powodu na początku Idei I filozof na nowo definiuje wykorzystywane przez siebie terminy. Takim pojęciem przykładowo jest „istota”. Ze względu na jego wieloznaczność Husserl woli je

7 R. Ingarden, U podstaw teorii poznania, Warszawa 1970, 232-233. 
zastąpić pojęciem eidos ${ }^{8}$. Intencja autora Idei, jak najbardziej uzasadniona, nie uwalnia jednak jego fenomenologii od problemów związanych z językiem. Za jej przyczyną, niestety, fenomenologia przestaje być - jeśli można tak powiedzieć - czujna. Powtórzmy raz jeszcze za Ingardenem: „Metoda ta więc unika wszelkich hipotez lub założeń czysto pojęciowych, unika również (...) wszelkich czysto pojęciowych rozumowań czy wnioskowań (...)”. Można zgodzić się z Ingardenem i pośrednio z Husserlem dopiero wtedy, gdy potraktuje się język jako medium przezroczyste, $z$ jakim mamy do czynienia np. wtedy, gdy zakładamy okulary przeciwsłoneczne. W przypadku języka tak jednak nie jest i przykład pracy Witolda Płotki to potwierdza.

Autor Studiów wielokrotnie powtarza, że fenomenologicznemu ufundowaniu wiedzy obce są wnioskowania. Przypadek percepcji ma być tego najlepszym przykładem. Czy jednak tak jest? Płotka powiada: „Obecność noez w korelacji z noematem w przypadku percepcji trafniej, jak sądzę, wyjaśnia horyzontalność postrzeżenia; percypowaną rzecz można mianowicie postrzegać pod wieloma aspektami i zawsze będzie ona obecna »w tym aspekcie«, a zatem dom można postrzegać zarówno jako dom-jako-niebieski lub dom-jako-Kowalskich itd."9. Proces opisany przez Płotkę może tak wyglądać, niemniej należy stwierdzić, że każdemu przeżyciu towarzyszy pewna forma rozumowania, którą można określić mianem inferencji materialnej ${ }^{10}$. Co to znaczy? Odwołajmy się do przykładu domu: jeżeli wiem, że dom Kowalskich jest niebieski, to jednocześnie wiem, że nie jest on brązowy ani żólty. Skoro jest on czyimś domem, czyli

8 E. Husserl, Idee czystej fenomenologii i fenomenologicznej filozofii, tłum. z niem. D. Gierulanka, Warszawa 1967, 22.

9 W. Płotka, Studia z fenomenologii poznania, dz. cyt., 179.

10 Inferencje materialne, które są oparte na semantycznych własnościach zdań, przeciwstawia się formalnym, czyli wnioskowaniom opartym na własnościach syntaktycznych. Husserl, a za nim Płotka, mówiąc o wnioskowaniach, wydają się myśleć o inferencjach formalnych. Na ten temat por. np. R.B. Brandom, Making It Explicit: Reasoning, Representing, and Discursive Commitment, Cambridge 1994. 
Kowalskich, to wiem również (bo wnioskuję), że jest on bryłą (bo tylko bryłę można czymś „wypełnić”). Zatem kiedy będę szedł po ulicy, spostrzegę tylko jego jedną stronę. Wiem to bez konieczności odniesienia się do jakiejkolwiek naoczności. Wiem to na podstawie znajomości zdań, w których używam wyrażeń „dom”, „widzieć” itd. ${ }^{11}$

W tym miejscu mogę przejść do kolejnego punktu rozważań Płotki, czyli do analiz tzw. wiedzy operacyjnej. Autor Studiów odróżnia wiedzę propozycjonalną (knowing-that) od operacyjnej (knowing-how) i powiada: „o ile ten pierwszy rodzaj wiedzy przedstawia się za pomocą zbioru zdań, które są rezultatem refleksji umysłu interpretującego działania intencjonalne, o tyle ten drugi rodzaj realizuje się w samym działaniu i nie może przybierać formy propozycjonalnej, ponieważ w przeciwnym razie nie mógłby stanowić podstawy do działania" 12 . Trudno się w tym miejscu zgodzić z Płotką. Nie ma logicznego przejścia od tego, że wiedza ma być niepropozycjonalna, do tego, że jest podstawą działania. Twierdzę, że jest wręcz przeciwnie. Właśnie

11 Jest jeszcze inny ważny aspekt tej historii. Mianowicie można przeciwstawić tutaj takie ujęcia, które uznają, że percepcja jest bezpośrednia w sensie psychologicznym, tym, które traktują ją pośrednio. Pierwsze podejście zakłada, że informacje nie są przetwarzane czy intepretowane przez system poznawczy, ale bezpośrednio odbierane ze środowiska. Por. J.J. Gibson, The Ecological Approach to Visual Perception. New York 2014. Jest to stanowisko, które - jak sądzę - można przypisać Husserlowi. Drugie zaś głosi, że każda informacja musi być w jakiś sposób przetworzona, zanim zostanie przez system poznawczy wykorzystana; por. R. Gregory, Perceptions as hypotheses, Philos Trans R Soc Lond B Biol Sci. 290(1980)1038, 181-97, oraz prace badaczy nad przetwarzaniem predykcyjnym (np. A. Clark, Whatever next? Predictive brains, situated agents, and the future of cognitive science, Behavioral and Brain Sciences 36(2013), 181-204. DOI: 10.1017/S0140525X12000477; A. Clark, Surfing Uncertainty. Prediction, Action and the Embodied Mind, Oxford University Press, Oxford 2016; J. Hohwy, The Predictive Mind, Oxford University Press, Oxford 2013). Zagadnienie to sprowadza się do pytania o to, w jaki sposób wykorzystywana jest już uprzednio posiadana wiedza w procesie odbioru nowych informacji ze środowiska. Istotne jest to, że psychologiczna pośredniość percepcji nie przesądza, że percepcja jest pośrednia w innych znaczeniach, np. metafizycznym czy epistemicznym. Takie postawienie sprawy powoduje, że można zupełnie inaczej odczytać polemikę Płotki z Dreyfusem czy Fodorem.

12 W. Płotka, Studia z fenomenologii poznania, dz. cyt., 211. 
dlatego, że może ona być propozycjonalna, to może ona stanowić podstawę działań. Kiedy kogoś zapytamy o motywy bądź rację jego działań, to uznamy go za osobę irracjonalną, jeżeli nie będzie umiał sformułować reguły bądź normy działania, czy po prostu podać racji, czyli wypowiedzieć zdania, które zracjonalizuje to, co robi ${ }^{13}$. Płotka swoje obserwacje opiera na koncepcji Huberta Dreyfusa, według którego taką wiedzą niepropozycjonalną jest tzw. wiedza ekspercka. „Wiedza ekspercka ze swej istoty nie daje się ująć w reguły, lecz nabywa się ją w długotrwałym treningu poprzez próby i błędy. (...) Argumentacja Dreyfusa ma na celu wykazanie, że reprezentacje mentalne w procesach wyjaśniania działania są zbędne" ${ }^{14}$. Wiedza ekspercka, konkluduje Płotka, opiera się więc na działaniach, „które nie korzystają z reguł, czyli też nie konstytuują się na podłożu "wiedzy-że«". Szereg rzeczy jest tu niejasnych. Wcześniej autor sugerował, że działania opierają się na wiedzy niepropozycjonalnej wyrażającej reguły, a teraz mówi się o działaniach nieopartych na regułach, które mają wiązać się z wiedzą propozycjonalną. Czy zatem mamy dwa rodzaje działań? Te oparte na regułach i takie, które na nich się nie opierają? Czym poza tym miałoby być działanie nieoparte na regułach? Działanie albo opiera się na jakichś regułach, albo nie jest działaniem ${ }^{15}$.

Kolejna sprawa, która stwarza trudności, to utożsamienie zbioru reprezentacji mentalnych z używaniem języka. Racje przemawiające za takim posunięciem nie są wystarczająco przedstawione. Nie jest

13 Por. D. Davidson, Action, Reasons and Causes, w: Essays on Actions and Events, New York 2001, 3-21.

14 W. Płotka, Studia z fenomenologii poznania, dz. cyt., 217.

15 Oczywiście może być tak, że nie istnieje określona reguła dotycząca takiego a nie innego działania. Nie wyklucza to jednak możliwości jej zrekonstruowania bądź wskazania pewnych elementów, które są konstytutywne dla danego działania, a bez których owo działanie nie mogłoby zostać zaklasyfikowane jako takie a takie. Przez regułę bowiem można rozumieć pewną normę działania (np. normę prawną), ale także określony wzorzec normatywny, który stanowi niejako matrycę dla określonej klasy działań (por. M. Piekarski, Od typiki doświadczenia do normatywnej antycypacji. Przyczynek do fenomenologii normatywności, Filo-Sofija 33(2016)2, 71-86). 
bowiem dobrze uzasadnione przekonanie, że język należy rozumieć w kategoriach reprezentacji ${ }^{16}$. Chociaż z drugiej strony Husserlowska koncepcja znaczenia jako referencji uprawnia takie myślenie. Problem Dreyfusa-Płotki dotyczący wiedzy eksperckiej opiera się na pomieszaniu dwóch porządków: porząadku wiedzy z porządkiem jej wypowiadalności. To, że ekspert nie formułuje swojej wiedzy wprost, wcale nie oznacza, że nie może tego zrobić. Dreyfus i Płotka mogą się z tym nie zgodzić. Dzieje się tak dlatego, że korzystają oni ze statycznej koncepcji języka, według której znaczenia są względnie stabilne, a kolejne zdania uzyskuje się albo na bazie nowych doświadczeń, albo na podstawie dedukcji. Dynamiczne i pragmatyczne koncepcje języka pokazują, w jaki sposób są i mogą być generowana nowe zdania w języku17. To, co tutaj określa się mianem wiedzy eksperckiej lub operacyjnej, można zredukować do poziomu wiedzy danej implicite, czyli potencjalnie wypowiadalnej. Pojawia się w tym kontekście otwarte pytanie o to, czy wiedza może mieć jakiś inny niż językowy charakter.

Przejdę teraz do kwestii tzw. momentu tetycznego. Płotka powiada: „Warstwą zewnętrzną wobec rdzenia jest moment tetyczny, czyli charakter uznania tego, co dane w bycie; moment tetyczny dotyczy różnego charakteru ujęcia danej treści w różnych, odpowiednich aktach. Nie sposób zaprzeczyć, że dany przedmiot inaczej

16 Wiele współczesnych ujęć języka zrywa zupełnie z reprezentacjonizmem na rzecz podkreślenia dynamicznej i enaktywnej relacji języka ze środowiskiem. Por. np. J. Rączaszek-Leonardi, I. Nomikou, K.J. Rohlfing, T.W. Deacon, Language Development From an Ecological Perspective: Ecologically Valid Ways to Abstract Symbols, Ecological Psychology 30(2018)1, 39-73.

17 Rozważania te rzucają nieco światła na problem tzw. mitu danych, sformułowanego przez Wilfrida Sellarsa. Płotka akcentuje ten problem mówiąc, że atak Sellarsa nie dotyczy fenomenologii ze względu na przyjmowaną przez nią koncepcję intencjonalnej materii i formy. Obrona ta jednak jest tylko pośrednia, bowiem właściwym przedmiotem ataku Sellarsa nie są teorie przyjmujące to, co bezpośrednio dane, ale takie, które przyjmują istnienie wiedzy nie-inferencyjnej, czyli opartej tylko na tym, co bezpośrednio dane. Taką teorią wydaje się być fenomenologia poznania. W. Sellars, Empiricism and the Philosophy of Mind, w: Minnesota Studies in Philosophy of Science, vol. 1, red. H. Feigl, M. Scriven, Minneapolis 1956. 
prezentuje się w percepcji, w wyobrażeniu, czy we wskazaniu jedynie językowym"18. Przedmiot może być więc dany wraz z przekonaniem o jego istnieniu. Czy oznacza to, że w percypowaniu, wyobrażaniu sobie czy przypominaniu obok właściwego przeżycia naocznego mamy współtowarzyszące sądzenie? Rozumiem to następująco: spostrzegam drzewo i jednocześnie wydaję sąd, czyli stwierdzam jego istnienie. Widzenie drzewa = uznanie drzewa $\mathrm{w}$ bycie. Co zatem decyduje o charakterze aktu? Jego hyle i morphe, czy może moment tetyczny/sądzeniowy? Bowiem, jeżeli widzę drzewo i uznaję je za realne, to spełniam akt percepcji. A czy w sytuacji, w której widzę drzewo i uznaję je za coś minionego, to realizuję akt przypominania sobie? Jaka jest relacja aktu do współwystępującego sądu? Na ile ten sąd można wiązać z językiem? Pozostawię te pytania bez odpowiedzi.

Dochodzę w tym miejscu do kwestii najbardziej palącej i wykraczającej znacznie poza poruszane tu problemy. Chodzi mianowicie o pytania, dotyczące relacji warstwy sądów do języka. Fenomenologowie znacznie chętniej mówią o sądach, sądzeniu, treści sądów niż o języku, jego użyciu bądź jego treściach. Czym jest sąd i jakie jest jego odniesienie do zdania? Sądzę, że jest to problem, którego nieprzemyślenie pokutuje $\mathrm{w}$ fenomenologii do dzisiaj. $\mathrm{Z}$ powodu uznania przez Husserla sądów za coś odrębnego od zdań, język stał się dla fenomenologii tematem drugorzędnym, skazując ją tym samym na tradycyjne, metafizyczne myślenie o znaczeniu zdań i ich roli w poznaniu oraz działaniu. Problemem nie jest tutaj, jak wielu może sądzić, „wzięcie języka w nawias”, ale zdanie sprawy z roli języka, jako jednego $z$ warunków konstytucji świata, obok świadomości, ciała czy podmiotu. Język bowiem to nie tylko referencjalnie rozumiane znaczenia, co zdaje się sugerować Ingarden, ale przede wszystkim pragmatyczny wymiar jego zastosowań, użyć i kontekstów, także tych wiedzotwórczych. Brak przeprowadzenia redukcji do, że się

18 W. Płotka, Studia z fenomenologii poznania, dz. cyt., 160. 
tak wyrażę, „żywego” języka, spowodował, że celne Husserlowskie intuicje dotyczące języka zostały „przeoczone”.

Zwróćmy uwagę na te przykładowe intuicje: rozważania dotyczące wyrażeń okazjonalnych oraz tzw. Spielbedeutungen ${ }^{19}$, a także próby dotyczące opisania relacji pojęć empirycznych do przedmiotów danych w doświadczeniu, dotyczące tzw. typiki doświadczenia ${ }^{20}$. Wydaje się, że lingwistycznie wzbogacona fenomenologia znacznie by się wzmocniła i odkryła całe nowe pola badawcze.

Przedstawiona przeze mnie krytyka niektórych tez głoszonych przez Witolda Płotkę, w żadnym stopniu nie miała na celu podważenia zasadności zainicjowanego przez niego przedsięwzięcia, a raczej wykazanie potrzeby uzupełnienia go o pewne, „językowe" wątki. Podkreślone przeze mnie słabości pokazują mimo wszystko, jak żywą i pouczającą może być dzisiaj refleksja fenomenologiczna. Książka Płotki nie jest łatwa, stanowi ona jednak bardzo dobre wprowadzenie do fenomenologii Husserlowskiej i jej epistemologicznych podstaw. Myślę, że z czasem wejdzie ona do kanonu polskich „lektur” fenomenologicznych.

\section{BIBLIOGRAFIA}

Brandom R.B., Making It Explicit: Reasoning, Representing, and Discursive Commitment, Cambridge 1994.

Clark A., Whatever next? Predictive brains, situated agents, and the future of cognitive science, Behavioral and Brain Sciences 36(2013), 181-204. DOI: 10.1017/ S0140525X12000477.

Clark A., Surfing Uncertainty. Prediction, Action and the Embodied Mind, Oxford 2016.

Davidson D., Action, Reasons and Causes, w: Essays on Actions and Events, New York 2001, 3-21.

Gibson J.J., The Ecological Approach to Visual Perception, New York 2014.

19 E. Husserl, Badania logiczne II/I, tłum. z niem. J. Sidorek, Warszawa 1999, 42.

20 Por. E. Husserl, Doświadczenie i sąd. Badania nad genealogią logiki, tłum. z niem. B. Baran, Warszawa 2013; oraz M. Piekarski, Od typiki do normatywnej antycypacji, dz. cyt. 
Gregory R., Perceptions as hypotheses, Philos Trans R Soc Lond B Biol Sci. 290(1980)1038, 181-97.

Hohwy J., The Predictive Mind, Oxford 2013.

Husserl E., Idee czystej fenomenologii i fenomenologicznej filozofii, tłum. z niem.

D. Gierulanka, Warszawa 1967.

Husserl E., Badania logiczne II/I, tłum. z niem. J. Sidorek, Warszawa 1999.

Husserl E., Doświadczenie i sqd. Badania nad genealogia logiki, tłum. z niem.

B. Baran, Warszawa 2013.

Ingarden R., U podstaw teorii poznania, Warszawa 1970.

Piekarski M., Od typiki doświadczenia do normatywnej antycypacji. Przyczynek do fenomenologii normatywności, Filo-Sofija 33(2016)2, 71-86.

Płotka W., Redukcja fenomenologiczna jako zapytywanie. Fenomenologia Husserla a problem pytania, Przegląd Filozoficzny. Nowa Seria 85(2013)1, 173-190.

Płotka W., Studia z fenomenologii poznania. Transcendentalna filozofia Edmunda Husserla a problem wiedzy, Gdańsk 2015.

Rączaszek-Leonardi J., Nomikou I., Rohlfing K.J., Deacon T.W., Language Development From an Ecological Perspective: Ecologically Valid Ways to Abstract Symbols,

Ecological Psychology 30(2018)1, 39-73.

Sellars W., Empiricism and the Philosophy of Mind, w: Minnesota Studies in Philosophy of Science, vol. 1, red. H. Feigl, M. Scriven, Minneapolis 1956.

Tugendhat E., Der Wabrheitsbegriff bei Husserl und Heidegger, Berlin 1970.

\title{
THE FOUNDATION OF PHENOMENOLOGY AND THE PROBLEM OF LANGUAGE. COMMENTS ON WITOLD PŁOTKA'S BOOK STUDIA Z FENOMENOLOGII POZNANIA
}

\begin{abstract}
The aim of this article is to discuss certain ideas from Witold Płotka's book Studia z fenomenologii poznania. Transcendentalna filozofia Edmunda Husserla a problem wiedzy (Studies in the Phenomenology of Cognition. The transcendental Philosophy of Edmund Husserl and the Problem of Knowledge). In particular, the article examines the issue of the place and significance of language considerations in the context of Husserl's phenomenology. The author considers whether language is a transparent medium, and whether it is a constitutive element of the content and character of the experience.
\end{abstract}

Keywords: language, phenomenology, material inference, knowledge, action

Michał Piekarski

m.piekarski@uksw.edu.pl

Uniwersytet Kardynała Stefana Wyszyńskiego w Warszawie, Instytut Filozofii

Wóycickiego 1/3, 01-938 Warszawa

DOI: 10.21697/spch.2019.55.4.06 